Área Abierta. Revista de comunicación

audiovisual y publicitaria

ISSN: 1578-8393 / ISSNe: 1578-8393

http://dx.doi.org/10.5209/ARAB.58637

\title{
Posmodernidad: Crisis? What crisis?
}

\author{
Carmen Azpurgua García-Jalón ${ }^{1}$
}

Recibido: 17 de enero de 2018 / Aceptado: 20 de marzo de 2018

Resumen. El presente artículo propone una revisión de la mirada fílmica en torno a la crisis de la posmodernidad. Tomando como punto de partida el análisis de sociólogos posmodernos de relieve, se repasan las tendencias fílmicas dominantes de los 80 y 90 para verificar, finalmente, la ausencia de una postura suficientemente crítica ante la crisis de la sociedad posmoderna. Además, el trabajo atiende a la experimentación de un giro en esta tendencia a comienzos del milenio, expresada en el cine múltiplex como exponente de este cambio. Por último, se concluye con la continuación de este viraje y la aparición de una nueva sensibilidad social en la creación cinematográfica, caracterizada por el renacimiento épico y el neoromanticismo como notas predominantes.

Palabras clave: Crisis; posmodernidad; neobarroco; realismo; cine múltiplex; metamodernidad.

\section{[en] Posmodernism; Crisis? What Crisis?}

Abstract. The present article proposes a revision of the film look around the crisis of postmodernity. Taking the analysis of prominent postmodern sociologists as a starting point, the dominant film trends of the $80 \mathrm{~s}$ and $90 \mathrm{~s}$ are reviewed to verify, finally, the absence of a sufficiently critical position in the face of the crisis of postmodern society. In addition, the work deals with the experimentation of a turn in this tendency at the beginning of the millennium, expressed in the multiplex cinema as an exponent of this change. Finally, it concludes with the continuation of this turn and the appearance of a new social sensibility in the cinematographic creation, characterized by the epic renaissance and neo-romanticism as predominant notes

Keywords: Crisis; Posmodernism; Neo-baroque; Multiplex cinema; Metamodernism.

Sumario. 1. Introducción. 2. Autocomplaciencia cinematográfica posmoderna. 3. Realismo posmoderno. 4. El múltiplex, un cine epifánico. 5. Cine metamoderno una nueva dirección. 6. Conclusiones. 7. Bibliografía

Cómo citar: Azpurgua García-Jalón, C. (2018) Posmodernidad: Crisis? What crisis?. Área Abierta. Revista de comunicación audiovisual y publicitaria, 18 (2), 233-244. http://dx.doi.org/10.5209/ ARAB.58637

1 Universidad Rey Juan Carlos (España)

E-mail: cazpurgua@gmail.com 


\title{
1. Introducción
}

En septiembre de 1975 el grupo británico de rock progresivo Supertramp, publicaba su cuarto álbum con el título "Crisis? What Crisis?". En la portada aparecía el montaje fotográfico de un individuo en bañador bajo una sombrilla, en mitad de un paisaje industrial lleno de fealdad. El título y la imagen son una buena síntesis de lo que hemos vivido en las cuatro décadas posteriores: la escéptica y apática negación del ideal.

\begin{abstract}
Ahora que ya se puede dar por muerta la posmodernidad, los nuevos teóricos del metamodernismo, la última dialéctica, afirman que la posmodernidad reprimió durante largo tiempo el deseo de un futuro mejor: "Empresarios, políticos, arquitectos y artistas están formulando una nueva narrativa del anhelo estructurada y condicionada por una creencia ('yes, we can' 'change we can belive in') ${ }^{2}$ que estuvo reprimida durante mucho tiempo, la posibilidad de (a 'better' future) se había olvidado" (Velmeulen \& Van den Akker, 2010: 5).
\end{abstract}

Desde el metamodernismo la posmodernidad es vista como una época de crisis inconclusa, como una indeterminación vacía sin propuesta teórica, un tren parado en vía muerta. No está exenta de claridad ni de agudeza esta visión y, de hecho, los sociólogos de lo posmoderno han apuntado a que la esencia de la posmodernidad es precisamente la falta de discurso (Lyotard, 1987), o el pensamiento débil (Vattimo, 1995).

Lyotard en su libro La condición posmoderna, escrito en 1979, señaló la pérdida de los metarrelatos ${ }^{3}$ como lo más relevante del paso de la modernidad a la posmodernidad. La incredulidad de esta etapa ha sido enorme, el hombre posmoderno no cree en Dios, ni en el progreso ilimitado, ni en la omnipotencia científica, ni en la sociedad sin clases, las explicaciones totalizantes le generan desconfianza. La posmodernidad ha vivido satisfecha de no tener ideal, de no ir en busca de explicaciones coherentes acerca de la existencia. La sociedad se ha considerado a sí misma adulta para enfrentarse sin miedo al vacío existencial.

Como contrapartida, ese escepticismo relativista ha generado inevitablemente una radical inseguridad. Si el hombre moderno pisaba firme sobre el suelo del pensamiento racional, la idea del progreso indefinido o la construcción del estado del bienestar, el individuo posmoderno, por el contrario, es un ser confuso movido por la ética de la indeterminación en la que todo es relativo.

Y, puesto que todo es relativo, cabe preguntarse: ¿dónde se sustenta la confianza del hombre posmoderno? Lyotard afirma que en la posmodernidad lo único creíble son las actuaciones. Los viejos criterios de legitimación han caducado, ya no nos preguntamos por lo justo y lo verdadero sino por lo útil, y en concreto nos interesa lo útil para nosotros, los niveles individuales, locales, particulares. En la sociedad posmoderna, según Lyotard, hemos abandonado la búsqueda de utilidades en contextos universales por el determinismo local. En definitiva el interés personal ha sido el

2 La cita del artículo de Velmeulen \& Van den Akker, "Notes on Metamodernism", recoge entre paréntesis los esloganes utilizados por el entonces senador demócrata Barack Obama, en la campaña primaria presidencial de 2008.

3 El metarrelato en Lyotard es un discurso totalizante y omnicomprensivo, que otorga explicación a hechos de carácter científico, histórico, religioso o social de forma absoluta, dando solución a toda contingencia. 
ámbito de actuación. Esta legitimación de lo útil ha causado cierto régimen de terror pues al no estar sustentada sobre base alguna, incurre en constantes contradicciones. Las incoherencias más palmarias de ese sistema de vida posmoderno se han dado en el campo socioeconómico, de modo que el capitalismo, fuera de toda ética, dejó de tener capacidad liberadora para convertirse en una fuerza autodestructiva (Lyotard, 1987).

Por su parte, Zygmunt Bauman habla de la sociedad posmoderna como una fase de la historia de naturaleza fluida, líquida. La forma sistemática para generar el paso de la modernidad a la posmodernidad fue "derretir los sólidos" o, dicho de otro modo, desligarse de las lealtades tradicionales para construir un nuevo y sólido orden (Bauman, 2000).

El proceso de disolución de los sólidos tuvo diversas etapas y, fue alcanzando todas las esferas de la vida humana consiguiendo cotas altísimas de desintegración, incluso en algunas de las estructuras sociales más compactas. Por medio de la liberalización, la desregulación, la flexibilización, la descentralización, la disminución de cargas, etc. el individuo consiguió una desvinculación cada vez mayor del sistema, al que ya no se está tan irresolublemente amarrado como en épocas anteriores (Bauman, 2000).

El hombre posmoderno ha conseguido el preciado bien de la emancipación, la liberación de cualquier tipo de amarra, ha llegado a la tierra prometida; sin embargo, Bauman pone en duda que esa tierra "mane leche y miel".

La ausencia de normas o su mera oscuridad — anomía-, es lo peor que le puede ocurrir a la gente en su lucha por llevar adelante sus vidas. Las normas posibilitan al imposibilitar; la anomia augura una imposibilidad lisa y llana. Si las tropas de la regulación normativa abandonan el campo de batalla de la vida, sólo quedan la duda y el miedo (Bauman, 2000: 26)

Quizá la estructura social más férrea haya sido secularmente la familia, y a este respecto Bauman se pregunta qué es una familia en la actualidad. Apropiándose de la terminología de Ulrich Beck, el sociólogo considera a la familia como una de "las categorías zombis" a la que pertenecen instituciones o estructuras sociales que están muertas y todavía vivas (Bauman, 2000).

Si esto ocurre en las relaciones familiares, tanto más sucede con el resto de los vínculos. Las relaciones laborales, de vecindario, de amistad, tienen un estatus muy precario, son más bien conexiones que se establecen en momentos determinados, ligazones temporales que han de poder desanudarse con facilidad. El hombre posmoderno se desenvuelve en las relaciones de forma contradictoria, mostrándose por una parte ávido de la seguridad de la unión y deseando relacionarse, y al mismo tiempo, con la permanente desconfianza hacia la atadura de estar relacionado "para siempre", temeroso de la carga que de seguro limitará su preciada libertad (Bauman, 2008).

La única excepción en el proceso de licuefacción, el único sólido que se ha mantenido en pie en la posmodernidad ha sido el dinero, si bien es cierto que también la economía ha experimentado su propio proceso de licuefacción liberándose de sus tradicionales ataduras, las trabas éticas y legales que frenaban el capitalismo salvaje en defensa del individuo han desaparecido paulatinamente. Impresiona leer a un profético Bauman del año 2000 a la luz de la crisis económica mundial de 2008, 
causada precisamente por la falta de regulación. El documental Inside Job (Inside Job, Charles Ferguson, 2010) trata con amplitud esta cuestión.

Se puede también observar cómo han sido modificados el trabajo y las estructuras laborales. Por difícil que pueda parecer, el capitalismo ha conseguido hacerse liviano a base de desprenderse de las grandes estructuras laborales de antaño; las enormes fábricas y los complejos sistemas de producción han sido sustituidas por estructuras económicas más ligeras. La empresa moderna está permanentemente a dieta buscando sin cesar la forma de adelgazar más. Los trabajadores sometidos de forma constante a reducciones de plantilla y regulaciones de empleo deben buscar formas de supervivencia: "para seguir con vida, los gerentes deben reducir los equipos de empleados, y los directivos deben reducir sus cargos gerenciales" (Bauman, 2000: 132).

Aunque la dificultad inherente a la vida laboral no es nueva, sí lo es la falta de herramientas del trabajador para enfrentarse al problema laboral: "El empleo se convierte en algo precario, y puede ser para muchas personas algo constantemente episódico: Los empleos seguros en empresas seguras resultan solamente nostálgicas historias de viejos" (Bauman, 2000: 171).

La perspectiva de Gilles Lipovetsky (1944-) considera que una de las características fundamentales de la sociedad posmoderna es la implantación de la cultura hedonista: el símbolo de nuestro tiempo es Narciso como de otras épocas lo fueron Fausto o Prometeo (Lipovetsky, 2003).

La posmodernidad sería la sociedad del neoindividualisno, del fin del hombre moderno o político, y el nacimiento del hombre psicológico o volcado en sí mismo. El horizonte del individuo posmoderno es "sentirse bien", y eso genera una sociedad que no reflexiona sobre grandes problemas ni se lamenta de sus grandes tragedias:

Nos acostumbramos sin desgarramiento a lo peor que consumimos en los mass media, nos instalamos en la crisis que por lo que parece no modifica los deseos del bienestar y de la distracción [...] el narcisismo ha abolido lo trágico y aparece como una forma inédita de apatía hecha de sensibilización epidérmica al mundo a la vez que de profunda indiferencia hacia él (Lipovetsky, 2003: 52).

Lipovetsky habla también de una sociedad volcada en la imagen que vive en una pantalla global (ordenadores, móviles, televisores, etc.). La impresión visual, la sensación, ha desplazado al sentido, se ha roto el discurso narrativo sustituyéndolo por la total heterogeneidad: "Cuando el significado deja paso a los juegos del significante y el propio discurso a la emoción directa, el narcisismo puede desarrollarse en toda su radicalidad" (Lipovetsky, 2003: 55).

La posmodernidad generaría por tanto una sociedad no determinada por ninguna metanarrativa, sin trabas ni normativa pero también sin proyecto unitario. La ética de la indeterminación y el relativismo propician un neoindividualismo que nos inclina hacia lo particular descuidando la construcción del bien común. La disolución del antiguo marco social determina las relaciones entre individuos disolviendo cualquier tipo de vínculo a excepción de las amarras indisolubles que genera el capitalismo salvaje. Pero quizá lo más sorprendente es la forma en que el hombre contemporáneo se ha adaptado a la situación instalándose en ella. 


\section{Autocomplaciencia cinematográfica posmoderna}

Entrando ya en el terreno de la representación audiovisual, comprobamos que sucede algo muy similar. Si revisamos la forma en que el cine de la posmodernidad ha ido enfrentando la realidad encontramos más aceptación que cuestionamiento, bien es cierto, que tampoco esto debería sorprendernos porque esa es, in extremis, la lógica posmoderna. La creación audiovisual se ha recreado en la situación de catástrofe aceptada y ha construido desde ahí sus señas de identidad. Hemos convivido durante décadas con un curioso sentimiento de autocomplacencia, con una parálisis asumida, con el estatismo más satisfecho: Crisis? What Crisis?

Lo más sobresaliente del cine posmoderno corresponde a la primera etapa, el neobarroco ${ }^{4}$ de los 80 y 90 fue un brillante ejercicio de reciclaje y combinación desorbitado en el que cualquier vestigio audiovisual anterior fue revisado y transformado. La aglutinación de componentes tradicionales del cine clásico y moderno, la hibridación genérica (Blade Runner, Ridley Scott 1982; Los intocables, Brian de Palma 1987; El cabo del miedo, Martin Scorsese 1991), los remakes paródicos (¡Aterriza como puedas! Jim Abrahams y Jerry Zucker 1980; Recuerdos, Woody Allen 1980), la exuberante intertextualidad (Eduardo Manostijeras, Tim Burton, 1990; Seven, David Fincher 1996; Mujeres al borde de un ataque de nervios, Pedro Almodovar 1988), la ruptura total de las coordenadas espaciotemporales (Reservoir Dogs, Quentin Tarantino 1992; El club de la lucha, David Fincher 1999; Annie Hall, Woody Allen 1977; Matrix, Larry y Andy Wachowski 1999), han cambiado la forma en que el espectador contemporáneo es capaz de ver cine. La locura creativa, lúdica y escéptica es la esencia cinematográfica de la época y lo que indudablemente permanecerá como distintivo de lo posmoderno.

Obsérvese que esta característica esencial de la posmodernidad está muy vinculada a la idea de Lipovetsky sobre el modo contemporáneo de asumir la tragedia, la parodia sería el medio para reafirmar el statu quo sin dramatismo y sin inquietud.

Desde ahí se explica también el interés permanente en la revisión del pasado, si no hay propuesta de futuro sólo nos queda la reinterpretación paródica del pasado y, al menos, "tomémoslo a risa"; la ironía se utiliza para desmitificar el discurso de la modernidad y las ideologías de verdades absolutas.

Otra de las grandes líneas del cine de la posmodernidad es la relativización de los valores morales instaurados, la licuefacción de los sólidos de la que habla Bauman. Para ello se muestran sin pudor comportamientos de violencia o sexo explícito considerados inmorales en el cine clásico y en el moderno: "La violencia juega un papel determinante, pero con una cotidianeización y un tratamiento distanciado que renuncia al discurso moral" (Sánchez Noriega, 2002: 560).

Efectivamente todo ese tipo de conductas consideradas anteriormente irregulares se muestran en exceso, con la pretensión de normalizarlas y, sin ningún tipo de juicio moral: la diversidad sexual, los nuevos tipos de familia, la droga, etc.

4 El término neobarroco fue acuñado por Omar Calabrese para definir la estética social de la época posmoderna. En su libro La era neobarroca, Calabrese analiza las complejas claves por las que se rige el gusto desde los ochenta y noventa. 


\section{Realismo posmoderno}

A partir de los 90 sin embargo, se comienza a vislumbrar una nueva dirección: "Tras los años de predominio del neobarroco postmoderno, se detecta una tendencia en el cine actual de filmes con preocupaciones sociales y planteamientos en los que se buscan soluciones más allá del "sálvese quien pueda", característico de la década anterior" (Schmidt, 2002:5)

Hay efectivamente una vuelta al realismo social de la mano de realizadores como Mike Leigh, Robert Guediguian, o los hermanos Dardenne y comienzan también a destacar cinematografías emergentes de corte neorrealista como la iraní, o la rumana. Estos realizadores tienen sin duda una perspectiva ética, en sus filmes "no sólo encontramos la descripción de la sórdida realidad actual, sino que se observa también la tendencia a presentar la viabilidad de una salida socialmente más positiva" (Schmidt, 2002:5)

No obstante, y a pesar de reconocer este giro en la producción audiovisual de los últimos tiempos, habría que preguntarse si este tipo de realismo social puede denominarse cine posmoderno. Hay que tener en cuenta que inicialmente el estilo realista se ha considerado excluido de los parámetros de la posmodernidad, que rechaza la mímesis y las formas narrativas lineales. Cinematografías como las anteriormente citadas no responden apenas a las características de la posmodernidad, por más que su temática sea la sociedad posmoderna, pues el tratamiento audiovisual desde el que la contemplan es de corte moderno.

La cuestión es si se puede dar al estilo realista clásico y moderno el giro posmoderno que se ha dado en otras formas de ficción y, si existe alguna forma de cine realista que, desde los parámetros posmodernos, ofrezca una salida más allá de la mera ironía desencantada.

Schmidt menciona en su artículo un realizador que en nuestra opinión es un buen ejemplo de lo que entendemos como realismo posmoderno: Aki Kaurismaki. El realizador finés trata problemáticas actuales desde un realismo no lineal, basado en el humor y la parodia, con un uso abundante de la elipsis y del esquematismo, que otorga especial importancia a aspectos formales como el color, y donde la música tiene una función referencial clave. Kaurismaki emplea los elementos esenciales del cine posmoderno, pero al mismo tiempo, su realismo muestra relaciones humanas llenas de dignidad y de ternura, en realidad ofrece una dirección ética.

Otro cineasta que encajaría en lo que entendemos por realismo posmoderno es Alejandro González Iñárritu. La multipremiada Birdman, supone una auténtica reinvención del estilo realista. En cuanto a temática es un catálogo completo de posmodernidad (familia disfuncional, fracaso de la paternidad, relaciones sin vínculos, adiciones, inmadurez), está escrita en clave irónica y paródica tomando el humor como forma de mitigar la opresión existencial, es barroca, excesiva y sin embargo realista. Es intertextual y metaficcional, pero sobre todo es epifánica, Iñárritu pretende que el espectador llegue a alguna parte, que concluya.

Junto a Kaurismaki y González Iñárritu, un tercer realizador que podría encajar en esta clasificación es Jim Jarmusch. Su modo de realización entra de lleno en la estética posmoderna. En cuanto a la temática, si bien es cierto que dentro de su filmografía hay un gran número de personajes perdidos en un mundo que no comprenden o del que se autoexcluyen, también lo es que se detecta con toda claridad el esfuerzo de búsqueda presente en los protagonistas de sus películas y que en los últimos tiempos, 
el director estadounidense ha dado un giro considerable hacia la dirección de la que venimos hablando. Paterson (2016), su última cinta, parece un lugar de llegada, los personajes han encontrado el significado de sus vidas.

Como se ve, no todo ha sido escepticismo desencantado, hay también autores puramente posmodernos capaces de esperanza, de retomar la senda de la ética propositiva, de aventurar caminos.

\section{El múltiplex, un cine epifánico}

Pero más allá del cine de realizadores concretos, querríamos centrar la atención en un tipo de películas que proliferaron a finales de los noventa y en los 2000 y que, en nuestra opinión, responden a las características del realismo posmoderno del que venimos hablando: el cine multi-historia, una clase de filmes cuyo argumento se construye siguiendo varias tramas distintas que ocasionalmente se cruzan.

Según Orellana y Martínez Lucena (2011) tanto por el número de películas que en las dos últimas décadas utilizan este tipo de narrativa, como por la homogeneidad de sus contenidos, se puede hablar ya de un sub-género dentro del género drama. Coincidimos con estos autores en dicha afirmación y también en la idea de que este subgénero se posiciona de forma crítica y reflexiva ante la posmodernidad algo que, como venimos explicando, ha estado escasamente presente en la cinematografía posmoderna.

Lipovetsky en La pantalla global habla del cine multitrama, al que se refiere como una categoría de "relatos múltiplex"; en adelante tomaremos prestada esa terminología (Lipovetsky, Serroy, \& Moya, 2009: 101).

Veamos las características de este tipo de cintas a fin de comprobar si reúnen las características del cine de la posmodernidad y hasta qué punto cuestionan el statu quo.

Como antecedentes del cine multitrama podemos mencionar películas como Rashomon (Rashomon, Akira Kurosawa, 1950), El azar (Blind Chance, Kieslowski, 1982) o posteriormente Pulp Fiction (Pulp Fiction, Quentin Tarantino, 1994) y Jackie Brown (Jackie Brown, Quentin Tarantino, 1997).

Pero consideraríamos como películas inaugurales del subgénero Gran Canyon, el alma de la ciudad (Lawrence Kasdan, 1991) y Vidas cruzadas (Short Cuts, Robert Alttam, 1993), a partir de ellas pueden enumerarse un gran número de producciones con puntos en común: Antes de la lluvia (Before the rain, Mitcho Mancheuski, 1994), Smoke (Wayne Wang, 1995), Magnolia (Paul Thomas Anderson, 1999), Traffic (Steven Soderbergh, 2000), Codigo desconocido (Code inconnu, Michael Haneke, 2000), Amores perros (Alejandro González Iñárritu, 2000), Vidas contadas (Thirteen Conversations About One Thing, Jill Sprecher, 2002), 21 gramos (21 grams, Alejandro González Iñárritu, 2003), Crash (Paul Haggis, 2004), Nueve vidas (Rodrigo García, 2005), Babel (Alejandro González Iñárritu, 2006). En versión española podemos citar entre otras La Soledad (Jaime Rosales, 2007) o Una pistola en cada mano (Ces Gay, 2012).

Empezando por sus características más reconocibles, las películas múltiplex trabajan con tramas simultaneas, historias a modo de mosaico que se van entrelazando hasta confluir en un punto de unión donde todo cobra sentido. Es lo que se llama narración en contrapunto, que consiste en narrar en forma entrelazada una serie de hechos acontecidos en diversos tiempos, en presentar estos tiempos como 
simultáneos, sin transiciones aclaratorias para el lector. Se utiliza la retrospección (vuelta al pasado) mezclada con el presente y el futuro.

Lo habitual en estos filmes es que ninguna de las tramas sobresalga por encima de las otras y que los personajes mantengan igualdad dramática, por lo que no se puede hablar de protagonistas frente a secundarios, sino más bien de una galería de secundarios.

Sin embargo, si hacemos una lectura más profunda acerca de quién es el héroe narrativo llegamos a la conclusión de que efectivamente existe un protagonista colectivo: el hombre posmoderno, un antihéroe confundido y desnortado.

La estructura narrativa está construida por medio de subtramas independientes que guardan una unidad temática de manera que la obra forma un todo expresivo. Lo que el autor intenta trasmitirnos no se alcanza con una sola historia, es necesario el conjunto de todas ellas para entender la totalidad del relato.

Un aspecto definitivamente posmoderno del cine múltiplex es el hipermontaje. Las películas de las que hablamos utilizan un montaje muy explícito, muy marcado, muy ágil. Es frecuente que empleen también innovaciones formales que pueden resultar algo forzadas pero que se justifican en este tipo de narrativa. Por citar algunos ejemplos, recordemos la pantalla partida que usa Jaime Rosales en La Soledad, el tratamiento del color para diferenciar las tramas que utiliza Steven Soderbergh en Traffic, o el uso del sonido que hace Iñárritu en Babel.

El montaje suele estar basado en la fragmentación y en el desorden temporal: comienzo in media res, prolepsis y analepsis, que provocan confusión y pérdida de control de la perspectiva espacio-temporal. Las películas múltiplex siguen la tendencia del cine posmoderno basado en la disgregación de las estructuras tradicionales, de modo que el discurso se organiza en microhistorias que, a su vez, desarrollan el continuum narrativo de forma fragmentada (Gordillo, 2008).

En cuanto a la ubicación las localizaciones del cine múltiplex son las grandes metrópolis, particularidad del género muy acorde con lo posmoderno. En Los Ángeles se desarrollan: Grand Canyon, Vidas cruzadas, Magnolia y Crash; en Nueva York, Smoke y Vidas contadas; en México D.F, Amores perros; En Paris, Código desconocido; en Memphis, 21 gramos.

Sobre la vida en las grandes metrópolis señala Lipovetsky: "cuanto más la ciudad desarrolla posibilidades de encuentros, más solos se sienten los individuos" [...] en todas partes encontramos la soledad, el vacío, la dificultad de sentir" (Lipovetsky, 2003: 78) y, si anteriormente decíamos que el protagonista colectivo en las películas múltiplex era el hombre posmoderno, también hay en cuanto al tema uno que indefectiblemente subyace en todas ellas: la soledad y el deterioro de las relaciones afectivas (Martínez Lucena, 2009). El cine múltiplex se desarrolla en contextos urbanos en los que el aislamiento y la agresividad hacen mella en el individuo.

Otra característica común a estos filmes es la forma en que el guion sustituye la causalidad (relación causa-efecto) por la casualidad, es el azar el que va empujando la narración. Casseti y Di Chio afirman que "las relaciones causales y lógicas son sustituidas por simples yuxtaposiciones casuales", es decir, la tramas se cruzan diegéticamente de forma azarosa (en Paredes, 2008:7). Efectivamente estas películas organizan las tramas en torno a accidentes casuales: automovilísticos, enfrentamientos con consecuencias fatales, disparos de armas sin sentido y cuestiones similares. Esto viene a subrayar la idea de la indefensión del hombre en manos de un destino contra el que no puede hacer nada, de la "no explicación". La inclusión de lo casual como 
eje narrativo tiene lógica aquí, soluciones que en otros guiones se considerarían un deus ex machina tienen sentido propio en las películas múltiplex.

En cuanto a la presentación de personajes hay un aspecto que guarda relación con la idea de Frederic Jameson sobre el tiempo en la posmodernidad. Jameson, otro de los grandes sociólogos de esta época afirma que nos movemos en un tiempo espacial presentista, sin vinculación con el pasado (1991). Esta cuestión se refleja en los personajes de las películas múltiplex cuya historia no suele aparecer, son gente que vive en el presente, en el hoy.

Otro aspecto interesante es la influencia en las películas múltiplex del discurso y la narrativa televisiva: el ritmo frenético en las imágenes en detrimento de los diálogos, el sentido episódico de las historias, las situaciones de mayor intensidad acompañadas musicalmente, el manejo de planos y cámaras y, sobre todo el hecho de que cada fragmento de historia no dura más que unos pocos minutos, recuerda al lenguaje de las series de televisión al que cualquier espectador contemporáneo está habituado (Paredes, 2008).

Quizá esta connaturalidad con el lenguaje televisivo sea lo que haya hecho posible que las películas múltiplex, que en principio pertenecen a un cine de autor poco comercial, hayan dado el salto con relativa facilidad al mainstream.

Los atributos del múltiplex mencionados hasta el momento se atienen rigurosamente a las características audiovisuales de la posmodernidad, cuestión que lo aparta del cine social que mencionábamos anteriormente.

Pero veamos una última seña identitaria que da título a este epígrafe: cine "epifánico". En nuestra opinión, se trata de una nota diferencial respecto a la corriente general de la cinematografía contemporánea y consiste en el hecho de que los filmes múltiplex sitúan al espectador ante sí mismo y en una postura crítica ante el sistema: "si queremos caracterizar de un modo completo el objeto de la denuncia de este tipo de cine, vemos que éste podría ser perfectamente la cultura narcisista y todos los malestares por ésta provocados" (Orellana \& Martínez Lucena, 2011: 246).

Las películas múltiplex están construidas de forma que toda su estructura apunta a una dirección: provocar una reacción epifánica en el espectador. La ausencia de protagonista hace que no haya un modelo identificativo claro para el espectador que, sin embargo, tiende a identificarse con la situación, lo cual propicia una personalización más rápida.

Según Marina Hassapopoulou (2008) la película multi-protagonista es un texto participativo en el que no es posible una absorción pasiva porque su propia dinámica provoca en el espectador el deseo instintivo de encontrar el sentido a lo que está viendo, de descubrir la unidad en lo aparentemente arbitrario.

Por último, el final abierto de las películas múltiplex, tanto desde el punto de vista argumental - las historias no concluyen-, como desde el punto de vista ético o moral, provoca necesariamente la interpretación del espectador que ha de sacar sus propias conclusiones para dar por terminada la película. Hay en el cine múltiplex una intencionalidad clara: provocar en el espectador viajes interiores de reconocimiento. Su mecanismo de construcción, abierto, interpelativo, a la búsqueda del sentido, produce la epifanía.

El cine múltiplex persigue una reacción en el espectador, pretende inducir una mirada crítica hacia la sociedad y por tanto podemos decir que la negación cinematográfica de la crisis empieza a cuestionarse finales de los noventa. Si el cine de los 80 y de los primeros 90 fomentó una impresión colectiva de sociedad más 
libre construyendo una autocomplacencia acrítica sobre otras características sociales menos positivas, a finales de los 90 se comienza a vislumbrar en algunos cineastas la decepción por el sistema de vida posmoderno, la queja de Lipovetsky salta al cine: "la sociedad posmoderna es aquella en que reina la indiferencia de masa, donde domina el sentimiento de reiteración y estancamiento" (2003:9). El individualismo feroz y la falta de implicación en la construcción de un bien común son las denuncias más claras de estos autores.

\section{El cine metamoderno una nueva dirección}

Pero ha sido necesaria la llegada de la metamodernidad para plantear con rotundidad una propuesta de puesta en marcha frente a la crisis. En la actualidad se detecta un cambio de paradigma, una demanda generalizada de sinceridad, unas renovadas ganas de creer y un distanciamiento del escepticismo posmoderno (Lorenzo Santana, Jorge, 2016).

Timotheus Velmeulen y Robin van den Akker mencionan el discurso de Obama del 28 de Enero de 2008: "Yes, we can" como inspirador del sentimiento metamoderno $\mathrm{y}$, efectivamente, encontramos algunos realizadores en la actualidad imbuidos de ese espíritu que alentaba el discurso presidencial. Wess Anderson y otros cineastas como Michel Gondry o Spike Jonze son exponentes claros del cambio de rumbo, su cine hace una relectura de la realidad apartándose de la visión cínica que mostraba la posmodernidad, oponiéndose al sarcasmo y a la indiferencia; continúan utilizando el filtro de la ironía pero en forma positiva y constructiva, como una forma de tener los pies bien anclados en la realidad, de manera muy diferente a como se utilizaba en la posmodernidad.

James Mc Dowell (2011) ha denominado el cine de estos directores "cine extravagante" o "cine peculiar", agrupando bajo esta denominación un tipo de películas indies de milenials y postmilenials que tienen en común un tono narrativo que oscila entre sinceridad e ironía, entusiasmo y desapego, ingenuidad y conocimiento.

En el tratamiento de los personajes el cambio de rumbo apunta al retorno del mito y del héroe comprometido, vuelve la épica, vuelve el deseo de pureza y de ingenuidad y por eso la infancia es uno de los lugares narrativos preferidos de este cine.

Películas como la citada Moonrise Kingdom (Wes Anderson, 2012), Viaje a Darjeeling (The Darjeeling Limited, Wes Anderson, 2007), Pequeña Miss SunShine (Little Miss Sunshine, Jonathan Dayton, 2006), Un lugar donde quedarse (Away We Go, Sam Mendes, 2009) o El amigo de mi hermana (Your Sister's Sister, Lynn Shelton, 2011) están centradas en personajes en búsqueda de sí mismos que necesitan vitalmente descubrir quiénes son (James Mac Dowell, 2011).

Algo anterior cronológicamente es el llamado cine de la "Nueva sinceridad" traslación cinematográfica de lo que David Foster Wallace profetizó en E Unibus Pluram: Television and U.S. Fiction (1993). La tesis de Wallace, temprana por aquel entonces, era que se avecinaba un regreso a la honestidad y a la sinceridad como rechazo de la ironía.

La caída de las Torres Gemelas fue el acontecimiento histórico que precipitó el cambio, la sinceridad fue la reacción lógica ante lo incomprensible. Cineastas como 
Todd Solondz, Neil LaBute o Alexander Payne comenzaron, a comienzos del nuevo milenio, a retratar la sociedad norteamericana desde una posición marcadamente crítica y honesta.

Analizando estos nuevos fenómenos cinematográficos Bolaño concluye que hay un deseo de recuperar el proyecto inacabado de la modernidad y un retorno a las grandes narrativas totalizadoras que comenzaron a desvanecerse después de los horrores de la Segunda Guerra Mundial. El aprendizaje de la posmodernidad, en forma de ironía, sería la válvula de seguridad que evitaría que esas narraciones totalizadoras se conviertan en pensamientos extremistas. Los creadores actuales ofrecen una posible solución a la crisis actual mediante la recuperación de viejos valores (Bolaño, 2014).

\section{Conclusiones}

El cine posmoderno, el neobarroco de los ochenta, creó sus señas de identidad desde una mirada escéptica de la realidad. Combatió el desencanto a través de la negación de la crisis, por medio de la ironía y el humor, renunciando a la ética y al ideal.

Después de un largo predominio de lo escéptico y cáustico, a finales de los 90 comienzan a detectarse filmes con capacidad de cuestionar los fundamentos sociales posmodernos. Casi todos los amagos en esta dirección provienen del campo realista, en este estilo, inicialmente alejado del paradigma posmoderno, surgen las propuestas más críticas hacia el statu quo. Realizadores como Aki Kaurismaki, Alejandro González o Jim Jarmusch, netamente posmodernos, se desmarcan del conformismo generalizado.

Pero quizá la propuesta más claramente reflexiva acerca de la quiebra posmoderna la tenemos en las películas múltiplex que, por sus características específicas y por su número desde finales de los noventa hasta la actualidad, pueden considerarse ya un subgénero cinematográfico.

El cine múltiplex está construido para conseguir que el espectador reflexione acerca de la vida contemporánea y pueda llegar a una experiencia epifánica de reconocimiento. El múltiplex reconoce la crisis posmoderna aunque todavía no es capaz de proponer una salida estructurada.

La metamodernidad, liberada ya del lastre posmoderno, busca con firmeza la salida de la crisis. Se observa un giro de la ficción hacia la nueva épica y al neoromanticismo desde una óptica pragmática, algo así como un retorno a la búsqueda del ideal con los pies bien anclados en la realidad.

\section{Bibliografía}

Bauman, Zygmunt. (2000). Modernidad líquida. Buenos Aires: Fondo de Cultura Económica. Bauman, Zygmunt. (2008). Amor líquido. Acerca de la fragilidad de los vínculos humanos. Madrid: Fondo de Cultura Económica.

Bretón, Luis. (2014). E.T.S. Arquitectura (UPM) La Nostalgia Operativa: un nuevo romanticismo. http://oa.upm.es/35547/ "Trabajo de Fin de Máster".

Bolaño, Jesús. (2014). "Filming Transcendentalism: The Place of Contemporary Independent Cinema in the Cultural Paradigm Shift". En Álvarez López, Esther (coord. and ed.), 
Building Interdisciplinary Knowledge. Approaches to English and American Studies in Spain. Oviedo: KRK ediciones.

Calabrese, Omar. (1994). La era neobarroca. Madrid: Cátedra.

Gordillo, Inmaculada. (2008). "La coherencia de la disgregación en el cine posmoderno: un viaje intercontinental a través de universos fílmicos fragmentados". Frame, vol. 3, pp. 142-153.

Hassapopoulou, Marina. (2008). "Babel: Pushing and reaffirming mainstream cinema's boundaries". Jump Cut: A Review of Contemporary Media, vol. pp. 50, 1-5.

Jameson, Frederic. (1991). El posmodernismo o la lógica cultural del capitalismo tardío. Barcelona: Paidós.

Lipovetsky, Gilles. (2003). La era del vacio: Ensayos sobre el individualismo contemporáneo. Barcelona: Anagrama.

Lipovetsky, Gilles y Serroy, Jean. (2009). La pantalla global: Cultura mediática y cine en la era hipermoderna. Barcelona: Anagrama.

Lorenzo Santana, Jorge. (2016). Facultat de Geografia i Història de la UB. Hacia una teorización del presente: discursos sobre arte y cultura en Occidente tras lo postmoderno. Recuperado de http://hdl.handle.net/2445/103342

Lyotard, Jean Francois. (1987). La condición postmoderna. Informe sobre el saber. Madrid: Ediciones Cátedra S.A. (Obra original publicada en 1979).

Mac Dowell, James. (2010). "Notes on Quirky". Movie: A Journal of Film Criticism, vol. 1, 1.

Martínez Lucena, Jorge. (2009). "El Cine multi-protagonista: Autenticidad, 'lenguajes sutiles' y 'lotta continua'”. Observaciones filosóficas, vol. 9.

Orellana, Juan y Martínez Lucena, Jorge. (2011). Celuloide posmoderno. Narcisismo y autenticidad en el cine actual. Madrid: Ediciones Encuentro.

Paredes, Eugenia. (2008). “Crash (colisión) de Paul Haggis”. Frame, vol. 3, pp. 258-269.

Rovatti, Pier Aldo y Vattimo, Gianni C. O. M. P. (1995). El pensamiento débil. Madrid: Cátedra.

Sánchez Noriega, José Luis. (2002). Historia del cine. Teoría y géneros cinematográficos, fotografía y televisión. Madrid: Alianza.

Schmidt, Margarita. (2002). "Realismo y humor en el cine actual". Área Abierta. Revista de comunicación audiovisual y publicitaria, vol. 3, 1. DOI:10.5209/ARAB.5110.

Velmeulen, Timotheus y Van den Akker, Robin. (2010). "Notes on metamodernism". Journal of Aesthetics \& Culture, vol. 2.1, pp. 56-77. DOI: 10.3402/jac.v2i0.5677.

Wallace, David Foster. (1993). "E unibus pluram: Television and US Fiction". Review of Contemporary Fiction, vol. 13(2), pp. 151-194. 